\title{
Market Women's Perception of Child Labour at Batati Market in Bida, Nigeria
}

\author{
Aliyu Mohammed ${ }^{1, *}$, Oyerinde Olufemi Oyesegun ${ }^{2}$ \\ ${ }^{1}$ Physical and Health Education Department, Federal College of Education, Kontagora, Nigeria \\ ${ }^{2}$ Department of Human Kinetics and Health Education, Bayero University, Kano, Nigeria
}

Email address:

mohammedaliyu503@gmail.com (A. Mohammed)

${ }^{*}$ Corresponding author

\section{To cite this article:}

Aliyu Mohammed, Oyerinde Olufemi Oyesegun. Market Women's Perception of Child Labour at Batati Market in Bida, Nigeria. International Journal of Education, Culture and Society. Vol. 4, No. 4, 2019, pp. 65-70. doi: 10.11648/j.ijecs.20190404.12

Received: July 17, 2019; Accepted: August 12, 2019; Published: September 10, 2019

\begin{abstract}
The study explored market women's perception of what constitutes child abuse and neglect in their daily interactions with their wards at Batati market. This main market in Bida was purposively selected and divided into five zones and using systematic sampling techniques, 40 shops owned by women were selected per zone. Two hundred women who consented participated in the study. One woman (owner or assistant) was interviewed per shop. A self-developed interview scheduled test for validity and reliability with correlation co-efficient result of 0.89 was used to collect data. Findings revealed that $65 \%$ and $60 \%$ had experienced street hawking and load carrying respectively during childhood. About $44.5 \%$ had stayed long hours in the market with their parents or relations. Majority (70\%) perceived load carrying services by children, and using children as beggar assistants as child abuse while scolding, beating and starving children were perceived as training measures rather than abuse. While the study revealed some degree of awareness about some behaviours that constitute child abuse and neglect certain other behaviours were not regarded as such. Implications for educational programmes among women in urban centres were highlighted.
\end{abstract}

Keywords: Batati, Bida, Child Labour, Market Women, Perception

\section{Introduction}

The United Nations Convention on the rights of the child [1] and the Organisation of African Unity (OAU) charter on the rights and welfare of the child remain the point of reference for defining what is child rights and monitoring. Nigeria, as one of the nations who are signatories to OAU charter on the rights and welfare of the child has since initiated, supported and collaborated with other national, international and non-governmental organisations to develop, implement and evaluate child rights monitoring programmes.

Print and electronic media enlightenment programmes, series of seminars and conferences, training programmes on child right advocacy are prevalent in Nigeria. Despite all these, various research endeavours continue to reveal socioeconomic, cultural, religious, ethnic as well as legal factors perpetuating different types of child abuse and neglect behaviours in different parts of the world as well as in
Nigeria [2-5]. The impact of abuse and neglect on the child has also been extensively researched $[6,7]$. Researchers have suggested that about a third of abuse survivors grow up to abuse their own children [8-10].

Considered from another perspective, different cultures have accepted child disciplinary measures with the result that what is considered child abuse and neglect in one culture is normal and genuinely thought to be in the best interest of the child in another culture.

Socializing children into the world of work by increasing their roles in productive activities is common in most rural communities in Nigeria. Exploitative child labour goes beyond labour within the family context. It has also been argued that there exists a high degree of exploitative child labour in family-run economic activities. Children under 15 years involved in trading activities without adequate remuneration and no decision-making role are therefore abused.

This aspect of child abuse has received the greatest 
attention in research. For example, United Nations International Children Education Fund [11] studied street children in Kaduna and Calabar while Oladepo [12], examined street children in Ibadan metropolis. In a publication of Child Development Department of Federal Ministry of Women Affairs and Social Development [13], the rights of the Nigerian child were stated in eleven articles. The tenth is on protection against exploitation and inhuman treatment. The document has messages in different aspects of exploitation and inhuman treatment to government, parents and even children. With regards to child labour, the main message states:

"Every child must be protected against all forms of exploitation, indecent or degrading treatment including child labour, abuse, torture, sexual exploitation, sale, abduction and drug abuse"

The message to government on child labour specifically includes:

1. Enforce legislative and administrative measures regulating terms and conditions for admission into labour market

2. Enforce penalties and sanctions to ensure the effective compliance with this right;

3. Mobilize public opinion against economic exploitation and child labour, which interferes with the child's physical, mental, spiritual, moral and social development in all sectors of the community.

The message to parents on child labour includes:

1. Understand their civic and social responsibilities regarding working children;

2. Protect children and wards from child labour abuse especially hawking or street trading;

3. Support government, non-governmental organisations and other institutions in monitoring and reporting cases of child exploitation to appropriate agencies

Five developmental stages that countries go through in addressing the problem of child abuse and neglect as follows have been identified by [3].

Stage 1-Denial of the problem

Stage 2-Paying more attention to the sensational and lucid aspect of abuse

Stage 3-Physical abuse is better handled and attention is paid to issues such as failure to thrive

Stage 4-Recognition of emotional abuse and neglect

Stage 5-Plight of sexual abuse is attended to

In underdeveloped and developing countries of the world, changes in traditional way of life, urbanization ad industrialization have led countries to recognize and identify increasing cases of child abuse and neglect. Even in developed countries of Western Europe, there are such heavy taboos on the subject of violence and abuse that denial still persists [3]. A similar situation exists in Nigeria now concerning the stages of our dealing with this phenomenon. For cultural, tribal and religious reasons, certain behaviours towards the child are still tolerated or defended either as training measures or child's normal role of assisting the parents rather than abuse and neglect.
In effect therefore, most societies still operate across the five stages depending on type of behaviour involved towards the child. In the market places in Nigeria, most of the workers are women who also keep many children around them as helpmates and spare hands.

The perception of these market women about the exposure of their wards to labour as these wards participate in almost every activity in the market is the focus of this study. This is with a view to determine the opinion of the sample about which of the activities the children engaged in constituted abuse and neglect. The impact of existing mass awareness and education programmes on child rights monitoring can also be indirectly assessed for the extent to which they have permeated the grassroots to the market women in Nigerian urban cities as to modify their perception.

The main thrust of this exploratory study was to find out how market women's previous experiences affect their perception of child labour with a view to providing recommendations to modify such practices that amount to child abuse and neglect in the community.

To guide the study the following research questions and hypotheses were developed. The research questions include:

i. What is the perception of market women of the major activities engaged in by children in the market?

ii. Does formal education influence market women's perception of certain activities engage in by children in the market as forms of child abuse?

iii. Does childhood business experience of market women influence their perception of children's activities in the market as forms of child abuse?

The null hypotheses were:

i. There is no significant difference in the perception of women with formal education and those without formal education with regard to child abuse and neglect.

ii. There is no significant difference in the perception of women who had past experiences of childhood in business activities and those who do not have with regard to child abuse and neglect.

\section{Methodology}

The survey was conducted at Batati market situated along Wuya road in Bida Town. The market women comprised mainly of Nupe and Yoruba selling articles, household wares, foodstuffs and clothes. The market, besides its daily operation also runs fortnight special sales drawing customers and sellers from other towns and villages around Bida, Niger State and beyond. The market has been fairly transformed from its original sheds to purpose-built and structured lockup shops with provision of security and payment of market dues to the Bida Central Local Government Authority for its maintenance.

Using systematic random sampling technique, the market was divided into five zones. Shops owned by women in each zone were identified and forty such shops were selected picking either every third or fifth shop in each zone. One woman from each shop (owner or adult assistant) who 
consented was interviewed using the self-developed interview guide. Using a two weeks test retest method, the guide was pre-tested for validity and reliability and confirmed appropriate at 0.89 score of correlation coefficient. It was prepared in English and Yoruba versions for understanding by subjects.

Two hundred subjects constituted the sample and data collected were analysed using descriptive and inferential statistics such as percentage and chi-square respectively.

\section{Results}

The respondents characteristics was analysed and presented in Table 1. From the table data gathered revealed that, majority $107(53.5 \%)$ of the market women sampled were between 26-35 years, 31(15.5\%) fell between 16-25 years while $62(31 \%)$ were within $36-41$ years and above bracket. Seventy respondents $(30 \%)$ had no formal education, $84(42 \%)$ had primary education while $44(22 \%)$ had secondary education and others.

Majority of them $102(51 \%)$ are Muslims while the rest $98(49 \%)$ are Christians. Majority $171(85.5 \%)$ are married while $12(6 \%)$ are single and widowed respectively. Five others are either separated $1(0.5 \%)$ or divorced $4(2 \%)$. Majority $178(89 \%)$ are Nupe while $21(10.5 \%)$ are Yoruba and one shop owner $(0.5 \%)$ belonged to other tribe.

Majority $108(54 \%)$ of the subjects had between 3-5 children, 61(30.5\%) had 1-2 children while 27(13.5\%) were blessed with 6-8 children. Four (2\%) respondents had 9 children or more. Table 1 represents a summary of the demographic characteristics of subjects.

Table 1. Demographic Characteristics of Subjects.

\begin{tabular}{|c|c|c|}
\hline Age in Years & Frequency & Percentage (\%) \\
\hline $16-20$ & 3 & 1.5 \\
\hline $21-25$ & 28 & 14 \\
\hline $26-30$ & 66 & 33 \\
\hline $31-35$ & 41 & 20.5 \\
\hline $36-40$ & 38 & 19 \\
\hline 41 and above & 24 & 12 \\
\hline Total & 200 & 100 \\
\hline \multicolumn{3}{|l|}{ Educational Level } \\
\hline No formal education & 72 & 36 \\
\hline Primary education & 84 & 42 \\
\hline Secondary school & 41 & 20.5 \\
\hline Others & 3 & 1.5 \\
\hline Total & 200 & 100 \\
\hline \multicolumn{3}{|l|}{ Religion } \\
\hline Islam & 102 & 51 \\
\hline Christianity & 98 & 49 \\
\hline Total & 200 & 100 \\
\hline \multicolumn{3}{|l|}{ Marital Status } \\
\hline Single & 12 & 6 \\
\hline Married & 171 & 85.5 \\
\hline Separated & 1 & 0.5 \\
\hline Divorced & 4 & 2.0 \\
\hline Widowed & 12 & 6.0 \\
\hline Total & 200 & 100 \\
\hline
\end{tabular}

\begin{tabular}{lll}
\hline Age in Years & Frequency & Percentage (\%) \\
\hline Ethnic Group & Frequency & Percentage (\%) \\
Nupe & 178 & 89.0 \\
Yoruba & 21 & 105.5 \\
Others & 1 & 0.5 \\
Total & 200 & 1000 \\
Parity & & \\
$0-2$ & 61 & 30.5 \\
$3-5$ & 108 & 54.0 \\
$6-8$ & 27 & 13.5 \\
9 and above & 4 & 2.0 \\
Total & 200 & 100 \\
\hline
\end{tabular}

Table 2. Subjects of Childhood Experiences of Forms of Child Labour and Treatment.

\begin{tabular}{lllll}
\hline \multirow{2}{*}{$\begin{array}{l}\text { Kinds of Child } \\
\text { Labour }\end{array}$} & \multicolumn{2}{l}{ Frequency } & Yes & \% \\
\cline { 2 - 5 } & No & \% & 130 & 65 \\
\hline Street hawking & 70 & 35 & 91 & 45.5 \\
Long hours of stay & 109 & 54.5 & 115 & 57.5 \\
Serious beating & 85 & 42.5 & 35 & 17.5 \\
Starvation & 165 & 82.5 & 89 & 44.5 \\
Isolation & 111 & 55.5 & 20 & 60 \\
Load carrying & 80 & 40 &
\end{tabular}

From table 2, analysis of respondents' childhood exposure to experiences of childhood labour revealed that $130(65 \%)$ of the sample did street hawking before, $120(60 \%)$ carried loads while $91(45.5 \%)$ had stayed long hours in the market as maids. Majority $115(5 \%)$ had experienced serious beating. Thirty-five $(17.5 \%)$ reported having been starved while $89(44.5 \%)$ had been isolated as a corrective measure in childhood.

Table 3. Respondents' Perception of Children's Business Activities in the Market.

\begin{tabular}{llllll}
\hline \multirow{2}{*}{ Activities } & \multicolumn{2}{l}{ Perception } & & & \\
\cline { 2 - 6 } & Positive & $\mathbf{\%}$ & Negative & $\mathbf{\%}$ & Total \\
\hline Load carrying & 60 & 30 & 140 & 70 & 200 \\
Street hawking & 128 & 64 & 72 & 36 & 200 \\
Beggar assistant & 50 & 25 & 150 & 75 & 200 \\
Long working & 39 & 19.3 & 161 & 80.5 & 200 \\
\hline
\end{tabular}

$\mathrm{N}=200$

In table 3, a higher percentage of the market women studied perceived the following activities as unfit labour for children to be engaged in the market-load carrying (70\%), beggar assistant $(75 \%)$ and long stay in the market $(80.5 \%)$. However, majority of them considered street hawking by children as good.

With regards to parental behaviours towards children, majority of the sample perceives scolding $(70 \%)$, serious beating $(59.5 \%)$, starvation $(55.5 \%)$ and use of abusive words $(53 \%)$ as positive corrective measures for child training. 
Table 4. Subjects' Perception of Children's Experiences in the Market as Abuse and Neglect by Education.

\begin{tabular}{|c|c|c|c|c|c|c|}
\hline \multirow[b]{2}{*}{ Educational Level } & \multicolumn{6}{|c|}{ Experiences perceived as abuse and neglect } \\
\hline & $\begin{array}{l}\text { Severe Bea } \\
\text { Yes }(\%) \mathrm{N}\end{array}$ & & $\begin{array}{l}\text { Starvatio } \\
\text { Yes }(\%)\end{array}$ & & $\begin{array}{l}\text { Use of ab } \\
\text { Yes (\%) }\end{array}$ & guage \\
\hline No formal education $(\mathrm{N}=72)$ & $48(60.7)$ & $24(33.3)$ & $23(32)$ & $33(45.8)$ & $33(45.8)$ & $39(54.2)$ \\
\hline Had a formal education $(\mathrm{N}=128)$ & $72(56.25)$ & $56(43.75)$ & $63(49.0)$ & $65(22.0)$ & $66(52.0)$ & $62(48.0)$ \\
\hline
\end{tabular}

$\mathrm{N}=200$

Analysis of subjects' perception of children's experiences in the market as abuse and neglect revealed that out of 72 respondents who had no formal education, majority $(66.7 \%)$ perceived only serious beating as child abuse. Majority of respondents $(68 \%)$ and $(54 \%)$ perceived starvation and use of abusive language as training measures.

Out of the 128 respondents with various levels of formal education, majority $72(56.25 \%)$ and $66(52 \%)$ perceived serious beating and use of abusive language respectively, as child abuse and neglect.

Table 5. Subjects by Childhood Business Experience and Perception of Activities Children Engage in the Market.

\begin{tabular}{|c|c|c|c|c|c|c|c|c|c|c|c|c|}
\hline \multicolumn{13}{|l|}{ Perception of Children's Activities } \\
\hline \multirow[t]{2}{*}{ Childhood Business Experience } & \multicolumn{4}{|c|}{$\begin{array}{l}\text { Street hawking } \\
\text { Positive+ Negative- }\end{array}$} & \multicolumn{4}{|c|}{$\begin{array}{l}\text { Long stay in market } \\
\text { Positive+ Negative- }\end{array}$} & \multicolumn{4}{|c|}{$\begin{array}{l}\text { Load carrying } \\
\text { Positive+ Negative- }\end{array}$} \\
\hline & + & $\%$ & - & $\%$ & + & $\%$ & - & $\%$ & + & $\%$ & - & $\%$ \\
\hline Had experience & 114 & 57 & 16 & 8 & 66 & 33 & 25 & 12 & 80 & 40 & 40 & 20 \\
\hline Had no experience & 10 & 5 & 60 & 30 & 29 & 14.5 & 80 & 40 & 25 & 12.5 & 55 & 27.5 \\
\hline
\end{tabular}

Analysis of subjects' perception of children's business activities in the market revealed that majority of those who had previous business experience in childhood were positive about children's engagement in street hawking whereas majority of those who had no experience have negative opinion.

With regards to long stay in the market $33 \%$ of the subjects had experienced it with positive perception while $7 \%$ viewed it negatively. Forty percent had no childhood experience and expressed negative perception while $20 \%$ had positive view. Load carrying by children, as a business experience was positively perceived by $40 \%$ of the subjects while $27.5 \%$ who had no experience had negative perception

\subsection{Educational Status of Respondents in Relation to Actions Perceived as Child Abuse and Neglect}

HO1: There is no significant difference between women with formal education and those without formal education with regard to their perception of child abuse and neglect.

Table 6. Perception of Severe Beating as Abuse and Neglect.

\begin{tabular}{llll}
\hline \multirow{2}{*}{ Educational Level } & \multicolumn{3}{l}{ Severe Beating } \\
\cline { 2 - 4 } & Yes & No & N \\
\hline No formal education & 48 & 24 & 120 \\
Had formal education & 72 & 56 & 80 \\
N & 72 & 128 & 200 \\
\hline
\end{tabular}

Cal. $x^{2}=2.083 ; d f=1 ; p=0.05 x^{2}=$ Tab. $=3.84$

Table 7. Perception of Child Starvation as Abuse and Neglect.

\begin{tabular}{llll}
\hline \multirow{2}{*}{ Educational Level } & \multicolumn{2}{l}{ Starvation } & \\
\cline { 2 - 4 } & Yes & No & N \\
\hline No formal education & 23 & 49 & 72 \\
Had formal education & 63 & 65 & 128 \\
N & 72 & 128 & 200 \\
\hline
\end{tabular}

$$
X^{2}=5.61 ; d f=1 ; p=0.05 X^{2}=\text { Tab. }=3.84
$$

Table 8. Perception of Use of Abusive Language as Abuse and Neglect.

\begin{tabular}{llll}
\hline \multirow{2}{*}{ Educational Level } & \multicolumn{4}{l}{ Use of Abusive Language } \\
\cline { 2 - 4 } & Yes & No & N \\
\hline No formal education & 33 & 39 & 72 \\
Had formal education & 66 & 62 & 128 \\
N & 72 & 128 & 200 \\
\hline
\end{tabular}

$$
X^{2}=0.61 ; d f=1 ; p=0.05 X^{2}=\text { Tab. }=3.84
$$

From Table 6, 7, and 8 above, there is no significant difference in the perception of respondents with formal and non-formal education as far as severe beating and use of abusive language are concerned but there is significant difference in their perception of starvation as a form of child abuse.

\subsection{Women's Perception of Some Experiences of Childhood Business Activities as Child Abuse}

HO2: There is no significant difference between women who had past experiences of childhood in business activities and those who do not have with regard to perception of child abuse and neglect.

Table 9. Perception of Street Hawking as a form of Child Abuse.

\begin{tabular}{llll}
\hline \multirow{2}{*}{$\begin{array}{l}\text { Childhood Business } \\
\text { Experience }\end{array}$} & \multicolumn{4}{l}{ Street Hawking as a form of Child Abuse } \\
\cline { 2 - 4 } & No & Yes & N \\
\hline No formal education & 114 & 16 & 130 \\
Had formal education & 10 & 60 & 70 \\
N & 124 & 76 & 200 \\
\hline
\end{tabular}

$$
X^{2}=104.06 ; d f=1 ; p=0.05 X^{2}=\text { Tab. }=3.84
$$


Table 10. Perception of Stay in a Market as a form of Child Abuse.

\begin{tabular}{llll}
\hline \multirow{2}{*}{ Educational Level } & \multicolumn{3}{l}{ Use of Abusive Language } \\
\cline { 2 - 4 } & No & Yes & N \\
\hline No formal education & 66 & 25 & 91 \\
Had formal education & 29 & 80 & 109 \\
N & 95 & 105 & 200 \\
\hline
\end{tabular}

$$
X^{2}=41.93 ; d f=1 ; p=0.05 X^{2}=T a b .=3.84
$$

Table 11. Perception of Load Carrying as a Form of Child Abuse.

\begin{tabular}{llll}
\hline Childhood Business & \multicolumn{4}{l}{ Load Carrying as a Form of Child Abuse } \\
\cline { 2 - 4 } Experience & No & Yes & N \\
\hline No formal education & 80 & 40 & 120 \\
Had formal education & 25 & 55 & 80 \\
N & 105 & 95 & 200 \\
\hline
\end{tabular}

$$
X^{2}=24.14 ; d f=1 ; p=0.05 X^{2}=\text { Tab. }=3.84
$$

Tables 9, 10, and 11 above showed that there are significant differences between respondents with formal and non-formal education with experiences of various forms of childhood business activities and those without such experiences in their perception of the identified actions as forms of child abuse.

\section{Discussion}

The three main activities that children were reported to be engaged in at Batati market studied included load carrying, street hawking, and staying long hours in the market. Most respondents who had experienced street hawking also perceived it as normal for children. This finding agrees with Oloko [14] who found the practice as normal in Northern Nigeria where it serves as marriage preparatory activity for girls. Education appears to influence seeing these business activities of children in the market as forms of child abuse as reflected in Tables 9-11. Majority of the subjects (54.5\%) had never experienced staying long hours in the market. $40 \%$ of these people were negatively disposed to keeping children for long hours in the market. On the other hand, out of the $45.5 \%$ of those who had long hours of stay childhood experience, $33 \%$ had positive disposition towards the practice. Previous experience seemed to have influenced these market women to either support or oppose keeping children in the market place for long hours.

With regards to load carry in the market by children as part of business activities, out of majority of the sample (60\%) who had the experience, $40 \%$ had positive attitude towards it while out of the 80 subjects $(40 \%)$ who had no childhood experience 55(27.5\%) expressed negative attitude towards exposing children to load carrying in the market. These findings confirm the principle of transactional theory of perception which involves the recognition that past experiences play an important role in perceiving any situation or event.

Formal education did not appear to positively influence respondents' perception of severe beating and use of abusive language as forms of child abuse. However, majority of respondents' were of the view that "a starved child will steal". Therefore, It will be important to investigate why many educated people would not see starvation as a form of child abuse in Nigeria especially in Batati.

Since the Nigerian society is historically an agrarian economy, which favoured bearing many children for use as cheap labour, the current situation of child involvement in various economic activities in the market can be understood. Kempe [3] also reported heavy taboos on the subject of violence as basis for persistence of the practice even in developed countries of Europe. Appreciating the need for evaluation of child rights monitoring programmes in Nigeria to determine their impact and relevance, this study is supporting the observation that the level of awareness of those acts that constitute child abuse and the attitude towards child labour among this group is poor particularly among those with childhood experiences who were supportive of child labour. The situation will positively influence their behaviour towards children thus posing new challenges to national efforts at discouraging child abuse of all forms.

\section{Conclusion and Recommendations}

The problem of child abuse and neglect will continue to attract the attention of researchers since the parental role and child rights will also continue to change from culture to culture as globalisation and industrialization increase. Downward trend in the economy, which tends to make more demand and promote parents trying to use all means of making extra money to be able to meet up with parental obligations will however influence the nature of change that may be expected. Nigeria should coordinate its child rights monitoring activities for effective and efficient mobilisation and actions to reach many more people, especially market women to educate them on the hazards of child labour.

Focal groups should further be identified for assessment of their attitudes towards the Nigerian child's involvement in economic activities with a view to increase their level of awareness and discourage the economic exploitation of children. Awareness campaigns on print and electronic media should be increased to discourage child labour at grassroots economic activities. Religious organisations as well as community based cultural and social groups, societies and non-governmental organisations should also be involved in activities to create awareness and modify behaviours of women as far as their attitudes to exposing children to business activities are concerned. Alternative approaches to improving sales in the market rather than use of young children needs to be explored.

\section{References}

[1] United Nations Convention on the Rights of the Child (1989) UNICEF.

[2] Wolfe, D. A. (1999). Child abuse: implications for child development and psychopathology, 2nd ed. Thousand Oaks, CA, Sage, 1999. 
[3] Kempe \& Kempe, H. (2007). Child Abuse, Cambridge, Harvard University Press.

[4] Opebiyi, A. (2005). Child Abuse Versus Human Right. The Guardian Sept. 11, p. 11.

[5] Jinadu, M. K. (2005). Child Abuse Prevention: The Role of Primary HealthCare. Child Abuse and Neglect 1 (1), 115-120.

[6] Frude, M. (1981). Psychological Approaches to Child Abuse. New Jersey: Bowman and Littlefield.

[7] Afamefuna, G. O., Wilson, E. B. (2003). Perception of Child Abuse and Neglect Among Nigerian Undergraduate Students. West African College of Nursing Journal, 2 (1), 4-9.

[8] Gelles, R. J. (1987). The Family and Its Role in the Abuse of Children. Psychiatric Annals, 17, 229-232.

[9] Wasik, B. H., Roberts, R. N. (1994). Survey of home visiting programs for abused and neglected children and their families. Child Abuse \& Neglect, 1994, 18: 271-283.
[10] Socolar, R. R. S., Runyan, D. K. (2001). Unusual manifestations of child abuse. In: Reece RM, Ludwig S, eds. Child abuse: medical diagnosis and management, 2nd ed. Philadelphia, PA, Lippincott Williams \& Wilkins, 2001: 453466.

[11] UNICEF (1981). Street Survey in Two Cities of Nigeria, UNICEF, Lagos.

[12] Oladepo, O. (2003). Street Children: An Assessment of Predisposing Factors in Ibadan Metropolis. Paper presented at National Launching of Child Rights Monitoring Centre in Ibadan, Nigeria.

[13] Child Development Department (1995). Nigeria and the rights of the child. Abuja: Fed. Min. of Women Affairs and Social Development.

[14] Oloko, B. A. (2004). Children Working in Urban Nigeria: A Case Study of Young Lagos Street Traders: Protecting Working Children edited by Meyers, UNICEF Publication. 